\title{
Pituitary Adenylate Cyclase 1 Receptor Internalization and Endosomal Signaling Mediate the Pituitary Adenylate Cyclase Activating Polypeptide-Induced Increase in Guinea Pig Cardiac Neuron Excitability
}

\author{
Laura A. Merriam, ${ }^{1}$ Caitlin N. Baran, ${ }^{1}$ Beatrice M. Girard, ${ }^{1}$ Jean C. Hardwick, ${ }^{2}$ Victor May, ${ }^{1}$ and Rodney L. Parsons ${ }^{1}$ \\ ${ }^{1}$ Department of Neurological Sciences, College of Medicine, University of Vermont, Burlington, Vermont 05405, and ${ }^{2}$ Department of Biology, Ithaca \\ College, Ithaca, New York 14850
}

\begin{abstract}
After G-protein-coupled receptor activation and signaling at the plasma membrane, the receptor complex is often rapidly internalized via endocytic vesicles for trafficking into various intracellular compartments and pathways. The formation of signaling endosomes is recognized as a mechanism that produces sustained intracellular signals that may be distinct from those generated at the cell surface for cellular responses including growth, differentiation, and survival. Pituitary adenylate cyclase activating polypeptide (PACAP; Adcyap1) is a potent neurotransmitter/neurotrophic peptide and mediates its diverse cellular functions in part through internalization of its cognate G-protein-coupled PAC1 receptor (PAC1R; Adcyap1r1). In the present study, we examined whether PAC1R endocytosis participates in the regulation of neuronal excitability. Although PACAP increased excitability in $90 \%$ of guinea pig cardiac neurons, pretreatment with Pitstop 2 or dynasore to inhibit clathrin and dynamin I/II, respectively, suppressed the PACAP effect. Subsequent addition of inhibitor after the PACAP-induced increase in excitability developed gradually attenuated excitability with no changes in action potential properties. Likewise, the PACAP-induced increase in excitability was markedly decreased at ambient temperature. Receptor trafficking studies with GFP-PAC1 cell lines demonstrated the efficacy of Pitstop 2, dynasore, and low temperatures at suppressing PAC1R endocytosis. In contrast, brefeldin A pretreatments to disrupt Golgi vesicle trafficking did not blunt the PACAP effect, and PACAP/PAC1R signaling still increased neuronal cAMP production even with endocytic blockade. Our results demonstrate that PACAP/PAC1R complex endocytosis is a key step for the PACAP modulation of cardiac neuron excitability.
\end{abstract}

\section{Introduction}

G-protein-coupled receptor (GPCR) activation recruits a cascade of signaling events to modulate cellular responses. Following signaling initiation at the plasma membrane, GPCRs are rapidly phosphorylated by GPCR kinases for $\beta$-arrestin recruitment and internalization via clathrin-dependent endocytosis (Calebiro et al., 2010). Although the endocytic machinery is considered to be a mechanism for signal desensitization and to follow trafficking routes for receptor lysosomal degradation or recycling, the divergent sorting of GPCR complexes into signaling endosomes represents another mechanism that generates cellular signals that may be distinct from those produced at the cell surface (Jalink and Moolenaar, 2010). Unlike the rapid events at the plasma

Received Oct. 24, 2012; revised Jan. 16, 2013; accepted Jan. 31, 2013.

Author contributions: V.M. and R.L.P. designed research; L.A.M., C.N.B., B.M.G., J.C.H., and V.M. performed research; L.A.M., C.N.B., B.M.G., J.C.H., and V.M. analyzed data; V.M. and R.L.P. wrote the paper.

This work was supported in part by NIH Grants P20 RR16435, P30 RR032135, and P30 GM103498 (to R.L.P.), and HL098589 (to J.C.H.). We thank Mr. Thomas Buttolph for his expert technical assistance and Dr. Anthony Morielli for helpful discussions during the course of this work.

The authors declare no competing financial interests.

Correspondence should be addressed to Dr. Rodney L. Parsons, Department of Neurological Sciences, College of Medicine, University of Vermont, Burlington, VT 05405. E-mail: Rodney.Parsons@uvm.edu.

DOI:10.1523/JNEUROSCI.4999-12.2013

Copyright $\odot 2013$ the authors $\quad 0270-6474 / 13 / 334614-09 \$ 15.00 / 0$ membrane, signaling at the GPCR endosomes is capable of generating sustained adenylyl cyclase/cAMP, MAPK/ERK, and phosphoinositide 3-kinase (PI3K)/Akt activation, which appear to be central to antiapoptotic and proliferation responses. Therefore, these internalization events not only regulate cell surface receptor density, but also provide alternative signaling platforms that can diversify signaling events to coordinate neuronal response programs.

Pituitary adenylate cyclase activating polypeptide (PACAP; Adcyap 1) is expressed in central and peripheral neurons and behaves as a neurotransmitter and neurotrophic peptide with critical roles in signaling, development, survival, proliferation, differentiation, and regeneration (Vaudry et al., 2009). We have demonstrated previously that PACAP is present in parasympathetic cholinergic preganglionic nerve terminals innervating guinea pig cardiac ganglia neurons (Braas et al., 1998; Calupca et al., 2000) and that neurally released or exogenous PACAP application depolarizes and increases cardiac neuron excitability via activation of the selective PAC1 receptor (PAC1R; Adcyap1r1) (Braas et al., 1998; Tompkins et al., 2006, 2007; Hoover et al., 2009). The increase in neuronal excitability persists with continuous PACAP exposure (Tompkins and Parsons, 2008; Tompkins et al., 2009; Merriam et al., 2012) and is suggested to be due in 
part to increased adenylyl cyclase/cAMP levels, which shift the voltage-dependent activation of the nonselective cationic conductance, $I_{\mathrm{h}}$ (Merriam et al., 2004; Tompkins et al., 2009). However, although the PACAP effect is seen in $90 \%$ of cardiac neurons, treatment with the cell-permeable cAMP analog 8-bromo-cAMP or the adenylyl cyclase activator forskolin enhances excitability in a significantly smaller fraction of the neurons (Tompkins and Parsons, 2008). Although earlier signaling pathway studies have excluded phospholipase C involvement, MAPK pathway activation does appear to participate in the PACAP/PAC1R-induced increase in excitability (Tompkins and Parsons, 2008). Because sustained adenylyl cyclase and MAPK activation are dependent on internalized receptor endosomal signaling in many GPCR systems, and because the PAC1R undergoes endocytosis upon ligand binding to activate neurotrophic signaling for cell survival (May et al., 2010), we investigated whether PAC1R internalization mediates the PACAP-induced change in excitability.

Our results show that the suppression of ligand-stimulated PAC1R endocytosis and membrane trafficking can blunt the PACAP-induced increase in neuronal excitability without altering cell surface signaling. The effect appears to be specific to endocytic mechanisms, because treatments to disrupt vesicular transport to and from the Golgi did not blunt the PACAP effect. These results demonstrate that PACAP/PAC1R complex internalization and endosomal signaling represent a critical mechanism supporting PACAP-induced changes in neuronal excitability.

\section{Materials and Methods}

Animals. All animal protocols were approved by the institutional animal care and use committees of the University of Vermont and Ithaca College and methods described in the NIH Guide for the Care and Use of Laboratory Animals. All electrophysiological experiments were completed in vitro using Hartley guinea pig atrial whole-mount preparations containing the intrinsic cardiac ganglia (either sex, 250-450 g). The guinea pigs were killed by isoflurane overdose and exsanguination; all efforts were made to minimize animal use and suffering. The heart was quickly removed and placed in cold standard Krebs' solution (in mм: $121 \mathrm{NaCl}, 5.9$ $\mathrm{KCl}, 2.5 \mathrm{CaCl}_{2}, 1.2 \mathrm{MgCl}_{2}, 25 \mathrm{NaHCO}_{3}, 1.2 \mathrm{NaH}_{2} \mathrm{PO}_{4}, 8$ glucose, $\mathrm{pH} 7.4$ maintained by $95 \% \mathrm{O}_{2}-5 \% \mathrm{CO}_{2}$ aeration) for atrial whole-mount preparation and intracellular recording, as described below.

Chemicals. PACAP27 was used exclusively in this study and is referred to as PACAP throughout the text. All drugs were obtained from commercial sources: PACAP27 was from American Peptide, brefeldin A was from Calbiochem/EMD Biosciences, Pitstop 2 ( $N$-[5-(4-bromobenzylidene)4-oxo-4,5-dihydro-1,3-thiazol-2 yl]naphthalene-1-sulfonamide was from Abcam Biochemicals, and dynasore was from Sigma). All drugs were applied directly to the bath solution from frozen concentrated stocks prepared in either DMSO (brefeldin A, Pitstop 2, dynasore) or water (PACAP). The concentration of DMSO in the bath solution never exceeded $0.1 \%$. Because dynasore is light sensitive, care was taken to minimize light exposure in these studies.

Intracellular recordings from neurons in whole-mount preparations. For intracellular recording, atrial whole-mount preparations were pinned in a Sylgard-lined chamber and superfused continuously $(6-7 \mathrm{ml} / \mathrm{min})$ with Krebs' solution containing $10 \mathrm{~mm}$ Na-HEPES buffer (Braas et al., 1998; Tompkins et al., 2006, 2007; Tompkins and Parsons, 2008). All experiments were performed with the bathing solution maintained at $32-35^{\circ} \mathrm{C}$, except studies to assess the temperature sensitivity of PACAPinduced excitability, for which all solutions were kept at ambient room temperature $\left(21-25^{\circ} \mathrm{C}\right)$. Individual intracardiac neurons were impaled under visual control using high impedance borosilicate microelectrodes ( $2 \mathrm{M} \mathrm{KCl-filled;} \mathrm{60-120} \mathrm{M} \Omega$ ). Membrane voltage was recorded from the impaled neurons using an Axoclamp-2A amplifier coupled with a Digidata 1322A data acquisition system and pCLAMP 8 software (Molecular
Devices). When necessary, hyperpolarizing current was injected through the recording electrode to ensure that action potential generation was tested at the same potential throughout an experiment. With current applied, the resting membrane potential was maintained between -55 and $-65 \mathrm{mV}$, values within the range of membrane potentials recorded from these cells.

Depolarizing current steps (0.1-0.5 nA for $1 \mathrm{~s})$ were applied to characterize neuron excitability (excitability trial). The response of mammalian cardiac neurons to long depolarizing current pulses can be classified as a phasic, rapidly accommodating, or tonic-firing pattern (Adams and Cuevas, 2004). PACAP enhances action potential generation elicited by long depolarizing pulses in all 3 classes of cardiac neurons. This reflects the PACAP-induced increase in excitability.

For statistical analyses, the cardiac neuronal responses in the different experimental conditions were grouped into just two firing patterns, phasic firing and multiple firing. Phasic cells fired 4 or fewer action potentials with increasing intensity of the $1 \mathrm{~s}$ current pulses up to $0.5 \mathrm{nA}$. Multiplefiring cells generated 5 or more spikes with the same increasing stimulus protocol. Multiple-firing cells included bursting (rapidly accommodating cells) and tonic cells (cells with action potentials generated over the duration of the depolarization) as long as the number of action potentials produced was 5 or greater. Excitability curves were constructed by plotting the number of action potentials generated by increasing stimulus intensities.

The effect of inhibitors on the PACAP-induced shift in excitability was tested in two different recording protocols. In the first, the ability of inhibitor (brefeldin A, Pitstop 2, or dynasore) pretreatment to suppress the PACAP effect was assessed. In the second, PACAP was first applied to phasic control cells and when excitability was enhanced, the ability of either Pitstop 2 or dynasore to reverse the PACAP-induced increase in spike generation was examined. In these experiments, hyperpolarizing current pulses were also applied to measure input resistance and to assess the presence of rectification in the voltage response. The presence of rectification, commonly used to demonstrate the activation of the inward current flowing through hyperpolarization-activated nonselective cationic channels (Edwards et al., 1995; Cuevas et al., 1997; Merriam et al., 2004), was quantified using the following equation: steady-state hyperpolarization $(\mathrm{mV})$ /initial hyperpolarization $(\mathrm{mV})$. To determine action potential amplitude and properties of the afterhyperpolarization (AHP) that follows a spike, neurons were stimulated directly with $1 \mathrm{~ms}$ of suprathresold depolarizing stimuli. The AHP amplitude represented the voltage change between the resting membrane potential and membrane potential at the peak of the AHP. To compare the time course of the AHP, AHP duration was measured at the voltage at which the amplitude decayed to one-third of the peak value.

To test neuronal excitability in general, either barium chloride (0.5-2 $\mathrm{mM}$ ) was added to the bathing solution (Tompkins et al., 2009; Merriam et al., 2012) or bethanechol (1 mM) was applied locally (6-8 psi for $1 \mathrm{~s})$ from a "puffer pipette" placed 50-100 $\mu \mathrm{m}$ from the cell (Girasole et al., 2010).

Primary sympathetic neuronal cultures and cAMP assays. Primary rat neonatal sympathetic superior cervical ganglion (SCG) neuronal cultures were used to quantify PACAP-induced cAMP production. The SCG neurons were prepared as described previously (Braas and May, 1999; Girard et al., 2002). In brief, 3-d-old rat pups were killed by decapitation and the SCGs quickly removed. The SCGs were then enzymatically dispersed to produce a pooled population of cells that were plated at a density of $1.5 \times 10^{4}$ neurons $/ \mathrm{cm}^{2}$ in collagen-coated 24 -well plates. The cultures were treated with cytosine $\beta$-D-arabinofuranoside to eliminate non-neuronal cells and maintained in defined complete serum-free medium containing $50 \mathrm{ng} / \mathrm{ml}$ nerve growth factor. Assays for PACAPinduced cAMP production in the primary sympathetic cultures were performed exactly as described previously (Braas and May, 1999; Girard et al., 2002). In studies examining temperature effects, the cultures were incubated with PACAP27 (20 nM) for $30 \mathrm{~min}$ at $24^{\circ} \mathrm{C}$ or $34^{\circ} \mathrm{C}$ in defined serum-free medium containing the phosphodiesterase inhibitor RO201724 (50 $\mu \mathrm{M}$; EMD Chemicals; $n=3-4$ wells per group). For drug treatments, the cultures were pretreated with either Pitstop 2 or dynasore for $10 \mathrm{~min}$ before PACAP addition and incubation for $30 \mathrm{~min}$ at $34^{\circ} \mathrm{C}$. 
The cultures were extracted in absolute ethanol containing $100 \mu \mathrm{M}$ RO20-1724 and processed for cAMP immunoassay using the Biotrak nonacetylation protocol (GE Healthcare). All samples and standard curves were performed in duplicate.

GFP-PAC1R transfection. The construction of the C-terminal GFPtagged PAC1R construct was described previously (May et al., 2010). HEK 293 cells were transfected using TransIT-LT1 transfection reagent (Mirus Bio) and cultured in DMEM/F-12 containing 8\% fetal bovine serum and $500 \mu \mathrm{g} / \mathrm{ml}$ Geneticin for stable cell selection. Individual cell colonies were selected and expanded; as before, functional expression of the receptor was assessed by GFP fluorescence and PACAP-stimulated second messenger activation. For PAC1R endocytosis experiments, the cultures were pretreated with $15 \mu \mathrm{M}$ Pitstop 2 or $20 \mu \mathrm{M}$ dynasore in serum- and BSA-free medium for $10 \mathrm{~min}$ before PACAP addition $(25 \mathrm{nM}$ PACAP27 final concentration) and incubation for $20 \mathrm{~min}$ at $37^{\circ} \mathrm{C}$. Studies examining temperature effects were performed similarly but at ambient temperature $\left(21-25^{\circ} \mathrm{C}\right)$. Upon experiment termination, the cultures were fixed with $4 \%$ paraformaldehyde, washed, and imaged with a Leica DMRB inverted fluorescence microscope equipped with a GFP filter set.

Statistics. Statistics were performed using Prism statistical version 5.4 software (GraphPad). Except as otherwise indicated, data are presented as mean \pm SEM. Differences among conditions that produced either phasic or multiple-firing responses were tested using the Fisher's exact test (see Figs. 2, 3, 4). Differences among means were compared with a two-tailed Student's $t$ test (paired or unpaired). The average number of action potentials produced during depolarizing step pulses was compared among conditions using an unpaired $t$ test (see Figs. 2, 3, 4). For Figures $5 B$ and $6 B$, the data were normalized to values in PACAP alone, but paired $t$ tests were performed on the actual values to determine significance. An unpaired $t$ test was used to determine differences in cAMP generation with temperature or drug treatment (see Fig. 7). Differences between means were considered statistically significant at $p<0.05$

\section{Results}

Endocytosis inhibitors and low temperatures block PAC1R internalization

The initial experiments in this study used HEK293 cells to establish that Pitstop 2 and dynasore suppressed internalization of the PAC1R. Similar experiments demonstrated that receptor endocytosis was suppressed at room temperature. In HEK293 cells transfected with the GFP-PAC1R construct, the PAC1R was localized predominantly on the cell surface, as shown by the green fluorescence surrounding each cell in Figure 1A. A few GFPPAC1R-containing vesicles were observed in the juxtanuclear Golgi region of the cell, suggesting that newly synthesized receptors were en route to the plasma membrane. The same cell surface expression pattern was observed whether the cells were held at $37^{\circ} \mathrm{C}$ or room temperature. When the transfected cultures were treated with $25 \mathrm{~nm}$ PACAP at $37^{\circ} \mathrm{C}$, the GFP-PAC1Rs were rapidly internalized via endocytic vesicles (Fig. 1C); the disappearance of cell surface GFP-PAC1R fluorescence within 10-20 min of PACAP application was accompanied by the appearance of numerous punctate vesicles dispersed in the cytoplasm. These receptor localization and internalization patterns were comparable to previous PAC1R immunocytochemical staining and trafficking data in intact and cultured sympathetic neurons (Braas and May, 1999; May et al., 2010).

Several studies have shown that endocytic and trafficking mechanisms are blocked at reduced temperatures (Teng and Wilkinson, 2003; McCann et al., 2008). In good agreement, PACAP treatment of the GFP-PAC1R cells at room temperature $\left(22-24^{\circ} \mathrm{C}\right)$ for $20 \mathrm{~min}$ failed to initiate significant endocytic events in the present study. As shown in Figure $1 B$, the GFP$\mathrm{PAC1R}$ fluorescence remained on the cell surface at levels com-
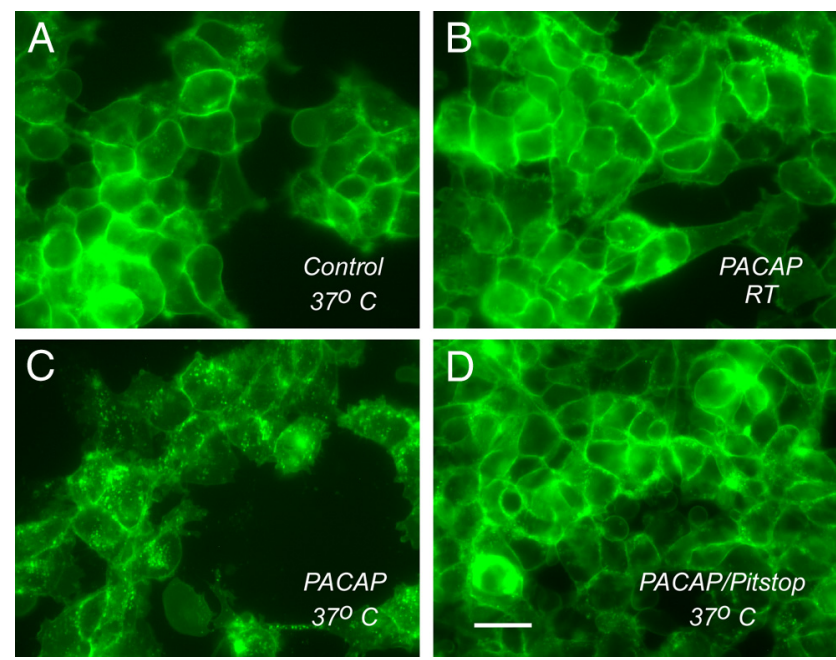

Figure 1. Pitstop 2 and room temperature (RT) block PAC1R endocytosis. $A$, GFP-PAC1Rs were expressed predominantly on the cell surface of transfected, untreated control HEK 293 cells; few intracellular GFP-PAC1R-containing vesicles were evident at $37^{\circ} \mathrm{Cor}$ room temperature (data not shown). C, The rapid internalization of GFP-PAC1Rs from the cell surface into numerous endocytic vesicles was evident after $25 \mathrm{~nm}$ PACAP addition (20 min). In contrast, maintaining the cultures at ambient room temperature $\left(22^{\circ} \mathrm{C} ; \boldsymbol{B}\right)$ or pretreatment of cells with $20 \mu \mathrm{m}$ Pitstop 2 (10 min; D) followed by $25 \mathrm{~nm}$ PACAP addition ( $20 \mathrm{~min}$ ) blocked GFP-PAC1R endocytosis. In both instances, the GFP-PAC1R fluorescence largely remained on the plasma membrane. Scale bar: (in $\boldsymbol{D}) \boldsymbol{A}-\boldsymbol{D}, 20 \mu \mathrm{m}$.

parable to those in the untreated controls (Fig. 1, compare $A, B$ ) without apparent changes in nascent endocytic vesicle formation.

Pitstop 2 has been used as a potent cell-permeable inhibitor of clathrin-mediated endocytosis by competing for clathrin terminal domain binding with box motifs (von Kleist et al., 2011). GPCR internalization typically enters clathrin-mediated pathways, and when HEK GFP-PAC1R-expressing cells were pretreated with Pitstop 2 before PACAP incubations at $37^{\circ} \mathrm{C}$, the receptors again were largely localized on the cell surface (Fig. 1D). However, inspection of the Pitstop 2/PACAP-treated cells revealed some endocytic PAC1R vesicle profiles under the plasma membrane apparently locked from trafficking even with prolonged incubation times. These observations appear comparable to the trapping of clathrin-coated vesicle intermediates attached to the plasma membrane (von Kleist et al., 2011). Dynasore, a dynamin I/II inhibitor that blocks vesicle scission from the plasma membrane, also blunted PACAP-stimulated GFP$\mathrm{PAC} 1 \mathrm{R}$ endocytosis at $37^{\circ} \mathrm{C}$, thus showing a pattern nearly identical to that observed for Pitstop 2 (data not shown).

\section{Endocytosis inhibitors block PACAP-induced neuronal excitability}

Parasympathetic cardiac neurons express PAC1Rs and, consistent with previous studies, $94 \%$ of the cells (15 of 16 neurons) shifted action potential generation from a phasic to a multiplefiring pattern after PACAP addition to the bath solution in the present study (Fig. 2A1,B). To determine whether PAC1R internalization might be required for the PACAP-induced increase in excitability, cardiac ganglia whole-mount preparations were pretreated with Pitstop 2 before initiating intracellular recordings. Pitstop 2 alone did not produce any noticeable change in action potential properties or excitability (data not shown). Unlike the increase in neuronal excitability observed after $20 \mathrm{nM}$ PACAP exposure, pretreatment with Pitstop 2 (15 $\mu \mathrm{M}$ for 7-20 min) blocked the PACAP-mediated responses. In 6 of 8 cell recordings, 

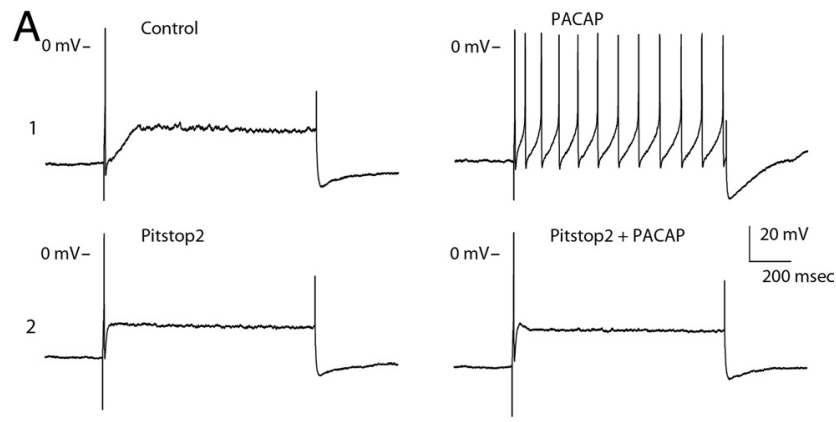

B
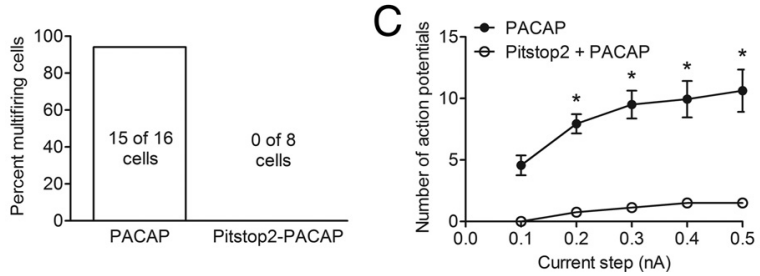

Figure 2. Pretreatment with Pitstop 2 suppresses the PACAP-induced increase in excitability. $A$, Recordings from 2 different cells. $A 1$ illustrates the increase in excitability induced by 20 nм PACAP. A2 shows that pretreatment with $15 \mu \mathrm{m}$ Pitstop 2 blocks the increase in excitability induced by $20 \mathrm{~nm}$ PACAP. For all recordings, a $1 \mathrm{~s}, 0.4 \mathrm{nA}$ depolarizing current step was used to initiate action potential activity. $\boldsymbol{B}$, The percentage of cells exhibiting multiple firing when exposed to PACAP alone $(n=16)$ was significantly greater than when exposed to PACAP after pretreatment with $15 \mu \mathrm{M}$ Pitstop 2 ( $n=8$; Fisher's exact test, $p<0.0001$ ). C, Averaged excitability curves show that Pitstop 2 greatly suppressed the PACAP-induced increase in excitability. Asterisks indicate that the number of action potentials generated at each current step was significantly greater in PACAP $(n=16)$ than in PACAP and Pitstop $2(n=8$; unpaired $t$ test, $p<0.0001$ for steps $0.2-0.5 \mathrm{nA})$.

the firing pattern after PACAP addition remained phasic throughout multiple trials. In the 2 remaining cells, a transient increase in excitability was noted after 4-6 min in PACAP; however, the shift in excitability was short-lived and by $10-12 \mathrm{~min}$, the PACAP-induced action potential generation had reverted and remained in the original phasic pattern for the remaining duration of the excitability trials (16-17 min in PACAP). The transient increase in excitability in Pitstop 2-pretreated cells was unique to the drug treatment, because it was not observed after PACAP treatment alone. For comparison with PACAP alone, the data from excitability trials determined at the end of all 8 experiments were compiled. At this time point, all Pitstop 2-pretreated cells exhibited a phasic-firing pattern despite continuous PACAP exposure (Fig. 2A2,B). The averaged excitability curves generated by increasing stimulus strength were markedly depressed in cells exposed to PACAP after Pitstop 2 pretreatment (Fig. 2C).

Barium treatment was used to ensure that the Pitstop 2 block of the PACAP-induced increase in excitability was not due to a general suppression of excitability. At a time when PACAP had no effect on excitability in $15 \mu \mathrm{M}$ Pitstop 2-pretreated neurons, the addition of barium could increase the number of action potentials elicited by depolarizing current pulses. For example, the maximum number of action potentials generated by a $0.4 \mathrm{nA}$ depolarizing pulse for $1 \mathrm{~s}$ was 2 and 3 in Pitstop 2-pretreated cells exposed to PACAP for $15-16 \mathrm{~min}(n=2)$. Four to $5 \mathrm{~min}$ after the addition of $1 \mathrm{mM} \mathrm{BaCl}_{2}$ to the Pitstop 2 and PACAP solution, the number of action potentials generated by the same depolarizing pulse was 10 and 9 , respectively.

We also investigated whether dynasore treatment would also blunt the PACAP-induced increase in excitability. Dynasore inhibits the dynamin I/II GTPase-mediated scission of endocytic vesicles from the plasma membrane (Herskovits et al., 1993; Macia et al.,
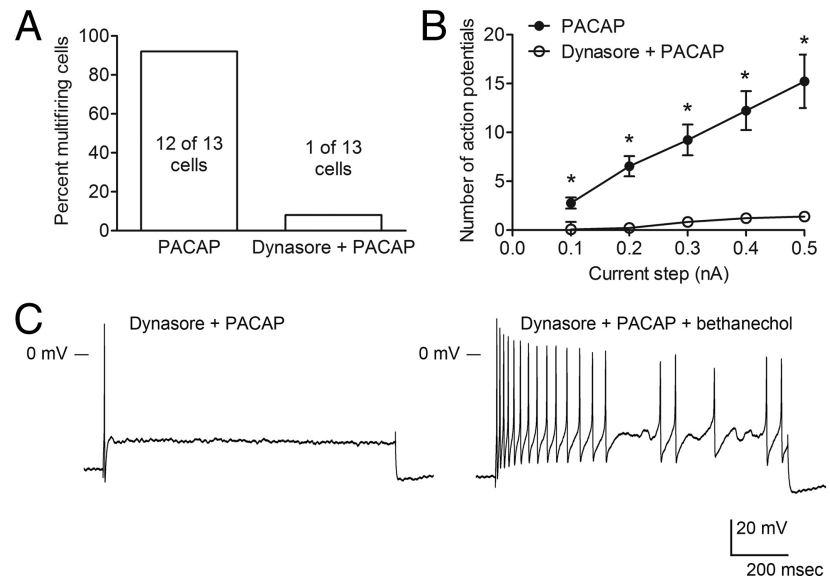

Figure 3. Pretreatment with dynasore suppresses the PACAP-induced increase in excitability. $\boldsymbol{A}$, The percentage of cells exhibiting multiple firing when exposed to PACAP alone $(n=13)$ was significantly greater than when exposed to PACAP after pretreatment with $20 \mu$ m dynasore $(n=13$; Fisher's exact test, $p<0.0001)$. $\boldsymbol{B}$, Averaged excitability curves show that dynasore greatly suppressed the PACAP-induced increase in excitability. Asterisks indicate that the number of action potentials generated at each current step was significantly greater in PACAP $(n=$ 13) than in PACAP and dynasore ( $n=13$; unpaired $t$ test, $p=0.0005$ for $0.1 \mathrm{nA} ; p<0.0001$ for $0.2 \mathrm{nA} ; p=0.0002$ for $0.3 \mathrm{nA} ; p=0.0001$ for $0.4 \mathrm{nA} ; p=0.0003$ for $0.5 \mathrm{nA}$ ). $C$, Recordings illustrated that bethanechol could increase excitability in a cell pretreated with dynasore and exposed to PACAP. Left trace shows the phasic-firing pattern generated by a $1 \mathrm{~s}, 0.4 \mathrm{nA}$ depolarizing current pulse in a cell pretreated with dynasore and exposed to PACAP. After local puffer application of bethanechol, the same depolarizing current step elicited multiple firing.

2006) and thus provides a separate mechanistic means of assessing the role of endocytosis in the PACAP-induced increase in cardiac neuron excitability. In a separate set of untreated control cardiac whole-mount preparations, bath application of $20 \mathrm{nM}$ PACAP induced a multiple-firing excitability pattern in 12 of 13 cells. Similar to the results with Pitstop 2, pretreatment of the ganglia whole-mount preparations with dynasore $(20 \mu \mathrm{M}$ for 5-20 $\mathrm{min}$ ) blunted the PACAP-induced increase in excitability. In 12 of 13 cells pretreated with dynasore, subsequent PACAP application only generated a phasic-firing pattern over the 70 min PACAP and dynasore exposure period, demonstrating that the PACAP-induced excitability was significantly suppressed. The remaining neuron exhibited a multiple-firing pattern, although only 5 action potentials were generated in response to the largest depolarizing step. Both the percentage of neurons exhibiting a multiple-firing pattern and the averaged excitability curves were significantly decreased in the dynasore plus PACAP preparations compared with cells exposed to PACAP alone (Fig. $3 A, B$ ).

As with Pitstop 2, dynasore did not nonspecifically suppress neuronal excitability. First, in the absence of PACAP, cells in dynasore-treated whole-mount preparations were capable of generating multiple-firing patterns when tested with long depolarizing current pulses (data not shown). Second, local puffer application of bethanechol could elicit multiple-firing patterns in control cells and in neurons treated only with dynasore (data not shown) or dynasore plus PACAP (Fig. 3C). Therefore, the results of the Pitstop 2 and dynasore studies suggest that PAC1R endocytosis is a requisite step in recruiting mechanisms regulating neuronal excitability.

\section{Brefeldin A pretreatment to block Golgi trafficking does not suppress PACAP-induced increases in excitability}

Clathrin is also thought to play trafficking roles between endosome and Golgi compartments (Bonifacino and Traub, 2003; Hirst et al., 2009). Therefore, we investigated whether brefeldin 
A, an antiviral antibiotic that interferes with endosomal budding (Drake et al., 2000) and trafficking to and from Golgi networks (Connors et al., 2008), affected the PACAP-induced increase in excitability. In 3 whole-mount cardiac ganglia preparations pretreated with brefeldin A (20 $\mu \mathrm{M}$ for 7-20 min), $20 \mathrm{nM}$ PACAP induced multiple-firing patterns in 5 of 6 cells. Therefore, brefeldin A had no apparent effects, suggesting that Golgi trafficking is not essential for the PACAP-induced increase in cardiac neuron excitability.

\section{Low temperature blocks both endocytosis and PACAP- induced increase in excitability}

To further establish that the results with Pitstop 2 and dynasore were not the result of unidentified pharmacological actions, we investigated the effect of temperature blocking of endocytosis on the PACAP-induced increase in excitability. Reducing ambient temperature has been used previously as a mechanism to block synaptic vesicle endocytosis (Teng and Wilkinson, 2003) and acetylcholine receptor $\alpha 7$ subunit internalization (McCann et al., 2008). PAC1R endocytosis was significantly depressed in cells exposed to PACAP at room temperature (Fig. 1), so the effects of temperature on the PACAP-induced excitability at $22^{\circ} \mathrm{C}$ (ambient room temperature) and $34^{\circ} \mathrm{C}$ were compared.

At room temperature, the PACAP-induced increase in excitability that had been seen consistently at warmer temperatures $\left(34^{\circ} \mathrm{C}\right.$ ) was no longer evident (Fig. $\left.4 A 2, B\right)$. All 10 cells tested at room temperature before PACAP exposure exhibited a phasicfiring pattern. During PACAP exposure at room temperature, only 3 of 23 cells (13\%) exhibited a multiple-firing pattern in response to the long depolarizing current pulses. The averaged excitability curves obtained at room temperature for untreated cells and PACAP-treated cells were not significantly different (Fig. 4C), nor were the curves different from untreated control data obtained at $34^{\circ} \mathrm{C}$. The temperature effects did not reflect a general suppression in cell excitability, because $2 \mathrm{mM} \mathrm{BaCl}_{2}$ enhanced action potential generation initiated by depolarizing current steps (Fig. 4A3). The temperature dependence of the PACAP-mediated increase in excitability is consistent with the pharmacological block of endocytosis and suppression of the PACAP effect on excitability.

\section{Pitstop 2 and dynasore can reverse the PACAP-induced increase in excitability}

To evaluate whether continuous PAC1R endocytosis and signaling are necessary events for the effects of PACAP on excitability, Pitstop 2 or dynasore was introduced into the bath solutions after the PACAP-induced increase in excitability was established. In this experimental paradigm, recordings were first obtained from a phasic cell before and after the addition of $20 \mathrm{~nm}$ PACAP. The PACAP-induced increase in excitability was allowed to develop over many minutes and, once a multiple-firing pattern was consistently recorded, either Pitstop $2(15 \mu \mathrm{M})$ or dynasore $(20 \mu \mathrm{M})$ was added to the PACAP-containing solution. Excitability was subsequently retested over a prolonged period with PACAP and either of the two inhibitors present.

In experiments with Pitstop 2, the drug was added after PACAP had increased excitability in six cells. In five cells, action potential generation gradually switched from a multiple to a phasic-firing pattern after Pitstop 2 addition to the PACAP solution. The time required for action potential generation to switch from multiple firing to phasic firing in these 5 cells varied from $\sim 6$ min to $\sim 16$ min (Fig. $5 A$ ). In the sixth cell, the impalement was lost after $9 \mathrm{~min}$ in Pitstop 2. At this time, the number of
$A_{1}$
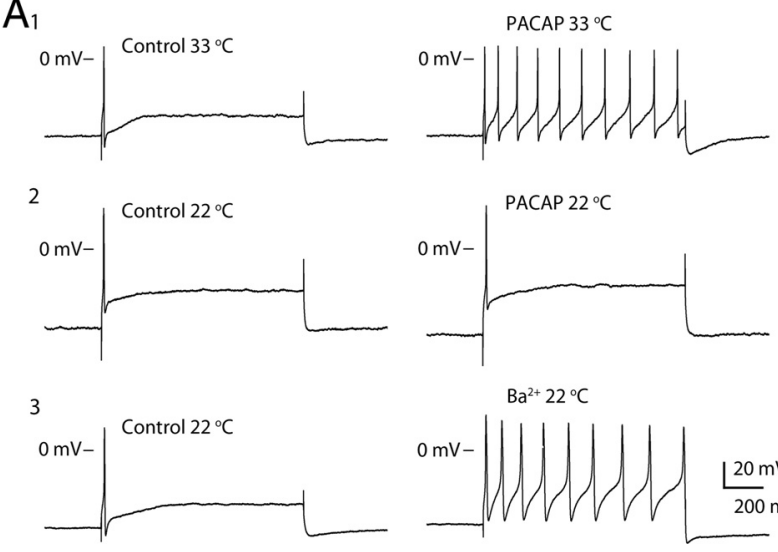

$\mathrm{Ba}^{2+} 22^{\circ} \mathrm{C}$

B
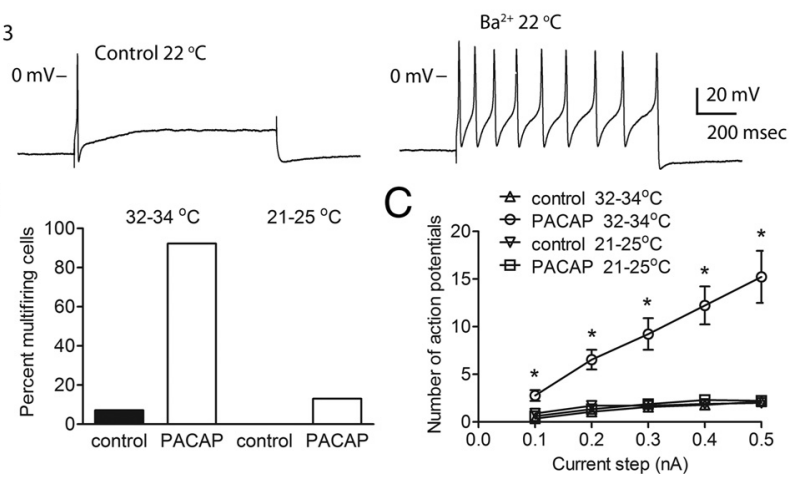

Figure 4. The PACAP-induced increase in excitability is temperature sensitive. $\boldsymbol{A}$, Recordings from different cells showed that $20 \mathrm{~nm}$ PACAP increased excitability when the bath solution was $33^{\circ} \mathrm{C}(\boldsymbol{A} \mathbf{1})$, but not when the bath temperature was $22^{\circ} \mathrm{C}(\boldsymbol{A} 2)$. The recording in $\mathrm{A}_{3}$ demonstrated that the addition of $1 \mathrm{~mm} \mathrm{BaCl}_{2}\left(\mathrm{Ba}^{2+}\right)$ increased excitability at $22^{\circ} \mathrm{C}$. In all three recordings, the cells exhibited a phasic-firing pattern before the addition of PACAP ( $\boldsymbol{A} \mathbf{1}$ and $\boldsymbol{A} \mathbf{2}$ ) or barium ( $\boldsymbol{A} \mathbf{3})$. The firing pattern shifted to multiple firing in $\boldsymbol{A} \boldsymbol{1}$ and $\boldsymbol{A} \mathbf{3}$, but not in $\boldsymbol{A} \mathbf{2}$. The amplitude of the $1 \mathrm{~s}$ depolarizing current pulse was $0.3 \mathrm{nA}$ in each experiment. $\boldsymbol{B}$, The percentage of cells exhibiting multiple firing in $20 \mathrm{~nm}$ PACAP was significantly greater when the temperature was $32-34^{\circ} \mathrm{C}$ $(n=13$ cells $)$ than when the bath temperature was $21-25^{\circ} \mathrm{C}(n=23$ cells; Fisher's exact test, $p<0.0001)$. At $32-34^{\circ} \mathrm{C}$ : control $(n=28)$ versus PACAP $(n=13)$, significantly different, $p<$ 0.0001 ; at $21-25^{\circ} \mathrm{C}$ : control $(n=10)$ versus PACAP $(n=23)$, not significant, $\left.p=0.5363\right)$. $C$ Averaged excitability curves generated in the cells maintained at either $33-34^{\circ} \mathrm{C}$ or $21-25^{\circ} \mathrm{C}$ before and during exposure to $20 \mathrm{~nm}$ PACAP. The number of action potentials generated at each current step was significantly greater (indicated by asterisks) at the warmer temperature in the presence of PACAP $(n=13)$ compared with control at warm temperature ( $n=28$; unpaired $t$ test, $p=0.0011$ at $0.1 \mathrm{nA} ; p=0.0002$ at $0.2 \mathrm{nA} ; p=0.0004$ at $0.3 \mathrm{nA} ; p=0.0002$ at $0.4 \mathrm{nA}$; $p=0.0005$ at $0.5 \mathrm{nA})$, and to PACAP at room temperature $(n=23$; unpaired $t$ test, $p=0.0029$ at $0.1 \mathrm{nA} ; p=0.0003$ at $0.2 \mathrm{nA} ; p=0.0005$ at $0.3 \mathrm{nA} ; p=0.0003$ at $0.4 \mathrm{nA} ; p=0.0005$ at 0.5 $\mathrm{nA})$. The number of action potentials generated at each current step was not different between control $(n=10)$ and PACAP $(n=23)$ at room temperature $(p=0.3502$ at $0.1 \mathrm{nA} ; p=0.4040$ at $0.2 \mathrm{nA} ; p=0.7132$ at $0.3 \mathrm{nA} ; p=0.4495$ at $0.4 \mathrm{nA} ; p=0.6642$ at $0.5 \mathrm{nA})$.

action potentials generated by a $1 \mathrm{~s}, 0.4 \mathrm{nA}$ depolarizing step had declined from 20 in PACAP alone to 16 action potentials after 9 min in Pitstop 2. We also tested in one cell whether the suppression by Pitstop 2 could be reversed by barium. In this example, the firing pattern was phasic ( 2 action potentials elicited by a $1 \mathrm{~s}$, $0.5 \mathrm{nA}$ depolarizing step) in PACAP and Pitstop 2, but 3 min after the addition of $1 \mathrm{mM} \mathrm{BaCl}_{2}$, the firing pattern became multiple firing ( 6 action potentials elicited by a $1 \mathrm{~s}, 0.5 \mathrm{nA}$ depolarizing step).

Using the same experimental regimen, dynasore also blunted the PACAP-induced excitability, but with more variability with respect to extent and time course of suppression of the PACAPinduced increase in excitability. In 5 cells, the change in excitability after the addition of dynasore was monitored for at least 20 min, whereas in the 6th cell, the impalement was lost 9 min after dynasore addition. In 1 of the 6 cells exposed to dynasore after PACAP had increased excitability, the dynasore effect was modest so that only a small decline in the PACAP-induced multiple firing occurred during the $20 \mathrm{~min}$ recording period (Fig. 6A). 
A

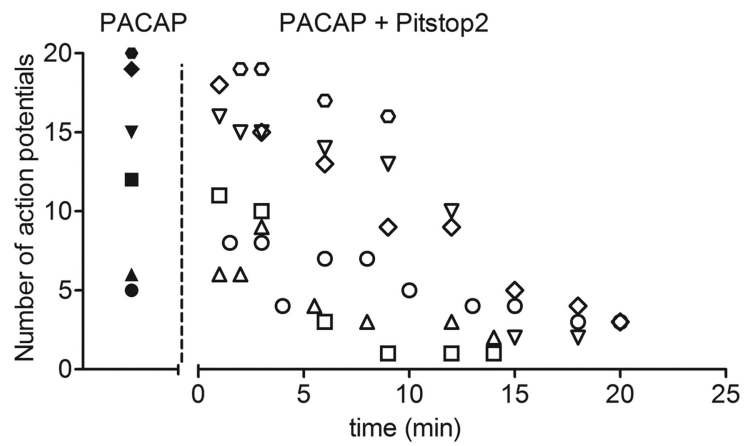

B

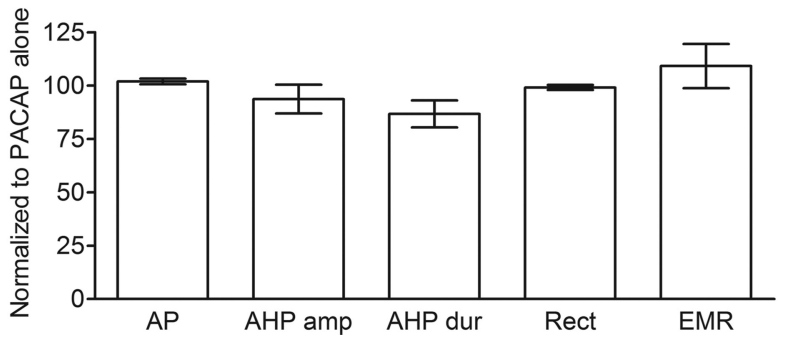

Figure 5. Pitstop 2 progressively reverses the PACAP effect after the increase in excitability has developed. $\boldsymbol{A}$, Results from 6 different cells in which $15 \mu \mathrm{m}$ Pitstop 2 was added after the PACAP-induced shift from a phasic- to a multiple-firing pattern had developed. Note that the number of action potentials elicited by the same stimulus $(1 \mathrm{~s}, 0.5 \mathrm{nA}$ for the cell indicated by the solid and open circles; $1 \mathrm{~s}, 0.4 \mathrm{nA}$ for the other cells) declined until action potential generation reverted back to a phasic-firing pattern in 5 of the 6 cells. In the sixth cell, the number of action potentials declined progressively until the impalement was lost. Each solid symbol represents data from one cell recorded in PACAP alone, followed in time by the corresponding open symbol representing the data recorded from the same cell after Pitstop 2 was applied. $\boldsymbol{B}$, Normalized data from the 5 cells that had returned to a phasic-firing pattern, which illustrated that the action potential amplitude (AP), AHP amplitude (AHP amp), AHP duration (AHP dur), the rectification occurring with hyperpolarizing steps (Rect), and effective membrane resistance (EMR) were not altered by Pitstop 2 at a time when the firing pattern was phasic ( $n=5$; paired $t$ test, AP: $p=0.2104$; AHP: $p=0.2359 ;$ AHP dur: $p=0.0882$; Rect: $p=0.4792$; EMR: $p=$ $0.6553)$. The results presented in $B$ are normalized to values obtained in the presence of PACAP before the addition of Pitstop 2.

In three other cells, the number of action potentials generated in the continued presence of PACAP and dynasore decreased progressively, but retained a multiple-firing pattern $(>5$ action potentials) throughout the recording period ( 9 and $20 \mathrm{~min}$; Fig. $6 A$ ). In two other cells examined, there was a shift from a multiple to a phasic-firing pattern (Fig. $6 A$ ). In one of these cells, $500 \mu \mathrm{M}$ $\mathrm{BaCl}_{2}$ was added to the PACAP and dynasore solution to ensure that excitability was not generally depressed in this cell. Within 5 min after the addition of barium, a shift from phasic (1 action potential elicited by a $1 \mathrm{~s}, 0.3 \mathrm{nA}$ depolarizing pulse) back to multiple firing ( 5 action potentials elicited by a $1 \mathrm{~s}, 0.3 \mathrm{nA}$ depolarizing pulse) occurred.

In previous studies of PACAP effects, we observed that the PACAP-induced increase in excitability was persistent and longlasting. To confirm this observation for the present study, we recorded excitability trials in 3 cells continuously exposed to PACAP alone for $>30 \mathrm{~min}$. The protocol was identical to that used to generate the data summarized in Figures 5 and 6. The results indicated that once the PACAP-induced increase in excitability had peaked, the number of action potentials elicited by repeated stimuli remained constant for $>20 \mathrm{~min}$. In these 3 cells, the average maximum number of action potentials generated initially in PACAP by a $1 \mathrm{~s}, 0.4 \mathrm{nA}$ step was $17.0 \pm 2.5$. The number of action potentials generated in multiple excitability trials during continued PACAP exposure did not change, so after
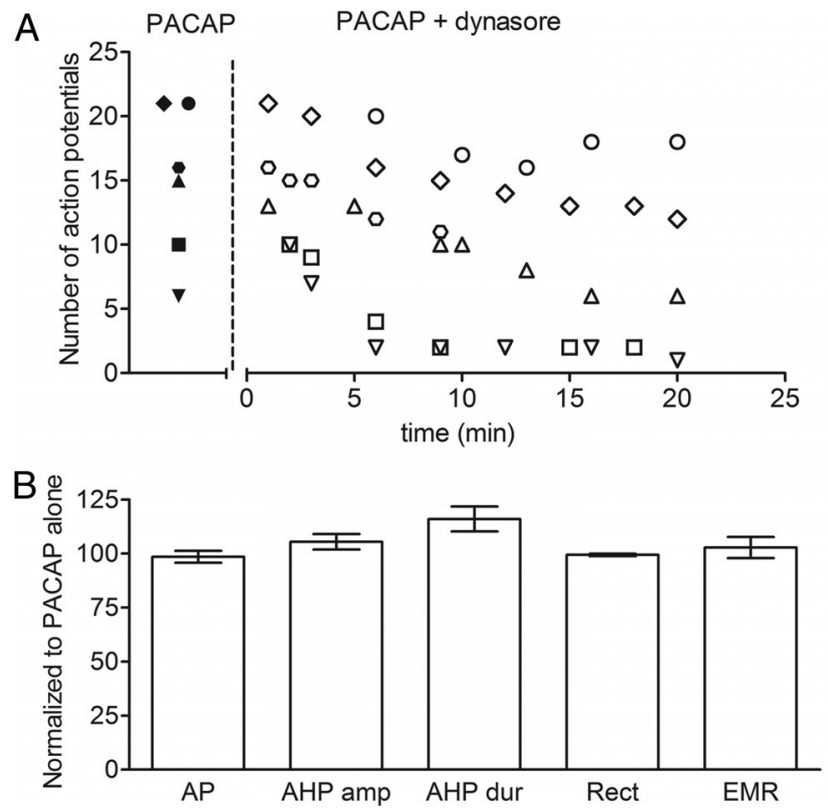

Figure 6. Dynasore reduces the PACAP effect after the increase in excitability have developed. $A$, Results from 6 different cells exposed to $20 \mu \mathrm{m}$ dynasore after the PACAP-induced shift from a phasic- to a multiple-firing pattern had developed. Each solid symbol represents data from one cell recorded in PACAP alone, followed in time by the corresponding open symbol representing the data recorded from the same cell after dynasore was applied. Note that the number of action potentials elicited by the same stimulus ( $1 \mathrm{~s}, 0.4 \mathrm{nA})$ declined over time in dynasore. In two cells, action potential generation reverted back to a phasic-firing pattern. In three other cells, although action potential generation declined, the firing pattern remained multiple at the time the recording was terminated. In the remaining cell, the firing pattern changed to a lesser extent in dynasore. $\boldsymbol{B}$, Normalized data from 5 cells illustrating that the action potential amplitude (AP), AHP amplitude (AHP amp), AHP duration (AHP dur), the rectification occurring with hyperpolarizing steps (Rect, and effective membrane resistance (EMR) was not altered by exposure to dynasore for $10-20 \mathrm{~min}(n=5$ paired $t$ test, AP: $p=0.5957$; AHP: $p=0.1863$; AHP dur: $p=0.0573$; Rect: $p=0.3437$; EMR: $p=0.8442$ ). The results presented in $\boldsymbol{B}$ are normalized to values obtained in the presence of PACAP before the addition of dynasore.

$20 \mathrm{~min}$, the number of action potentials generated by the same step was $16.7 \pm 1.8$ (paired $t$ test; $p=0.741801$ ). Therefore, in the presence of PACAP alone, excitability remained elevated for prolonged periods without noticeable decline.

We also evaluated in these experiments whether a Pitstop 2 or dynasore-induced change in action potential properties or rectification in hyperpolarizing steps could account for the reversal of the PACAP effect by these inhibitors. The membrane potential was maintained at $\sim-60 \mathrm{mV}$ electrotonically so that any differences noted would not be due to differences in resting membrane potential. Neither Pitstop 2 nor dynasore affected action potential amplitude, AHP amplitude or duration, or the input resistance in PACAP-treated cells (Figs. 5B,6B). Furthermore, the rectification noted during $500 \mathrm{~ms}$ hyperpolarizations was not affected by Pitstop 2 or dynasore (Figs. 5B, 6B).

\section{PAC1R-stimulated cAMP production is not dependent on endocytosis}

Our results suggested that the PACAP-induced increase in excitability was dependent on PAC1R endocytosis and resultant downstream signaling. Given that increased adenylyl cyclase/ cAMP signaling contributes to the PACAP effect and that adenylyl cyclase activity can be sustained in signaling endosomes (Calebiro et al., 2009; Ferrandon et al., 2009), we investigated whether the inhibitor- and temperature-dependent effects on 


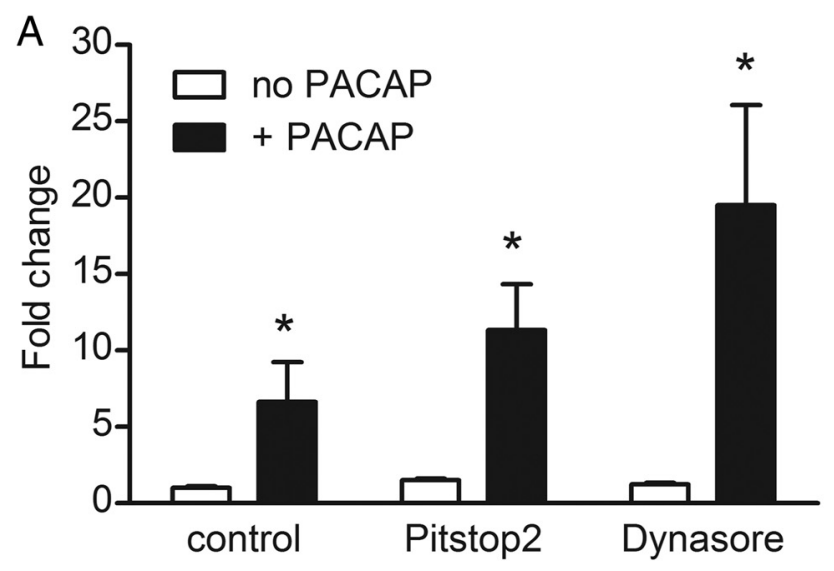

B

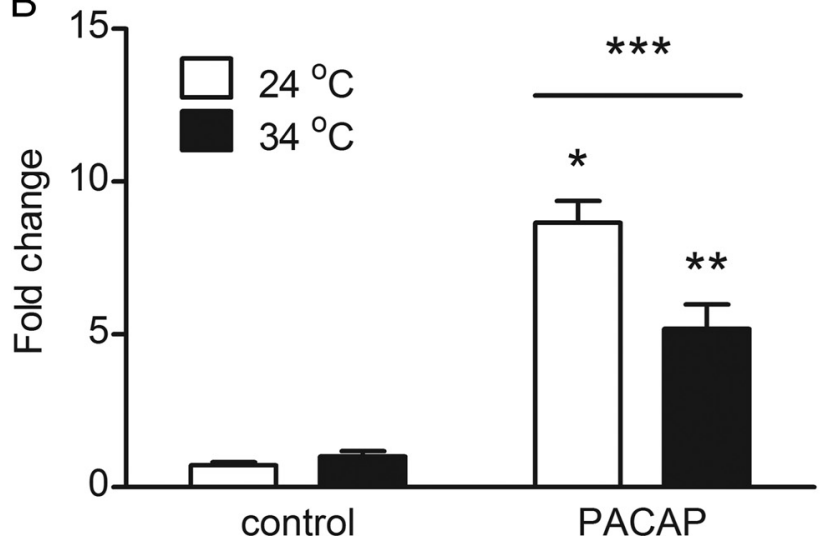

Figure 7. PACAP stimulates CAMP generation in dissociated rat neonatal SCG neurons after pretreatment with Pitstop 2 or dynasore and when cells are maintained at room temperature. A, PACAP increased cAMP production at $34^{\circ} \mathrm{C}$ after pretreatment with Pitstop 2 (10 min, $\left.15 \mu \mathrm{M}\right)$ or dynasore (10 min, $20 \mu \mathrm{m}$ ) and under control conditions. Values are expressed as the fold change of femtomoles/well determined at $34^{\circ} \mathrm{C}$. Asterisks indicate that the generation of CAMP by PACAP at $34^{\circ} \mathrm{C}$ in inhibitor-pretreated cells was significantly greater than with cells exposed to inhibitor without PACAP (unpaired $t$ test; $n=4$ in all cases; control vs PACAP, $p=0.0025$; dynasore vs PACAP + dynasore, $p=0.0144$; Pitstop 2 vs PACAP + Pitstop 2, $p=0.0058) . \boldsymbol{B}$, At $24^{\circ} \mathrm{C}$, PACAP $(n=3)$ significantly increased the generation of cAMP compared with control $(n=3) .{ }^{*} p=0.0004$, unpaired $t$ test. At $34^{\circ} \mathrm{C}$, PACAP $(n=3)$ significantly increased the generation of cAMP compared with control $(n=3) .{ }^{* *} p=0.0005$, unpaired $t$ test. The generation of CAMP was significantly greater at $24^{\circ} \mathrm{C}(n=3)$ than at $34^{\circ} \mathrm{C}(n=3)$ after a 30 min incubation in 20 nм PACAP. ${ }^{* * *} p=0.0315$, unpaired $t$ test. Values are expressed as the fold change of femtomoles/well determined at $34^{\circ} \mathrm{C}$.

PACAP-stimulated excitability reflected diminished cAMP production either at the plasma membrane or endosomal compartments. For these studies, primary sympathetic neuronal cultures were used to simulate PAC1R signaling responsiveness in autonomic neurons (Braas and May, 1999). Incubation of cultures with PACAP alone for $30 \mathrm{~min}$ at $34^{\circ} \mathrm{C}$ stimulated cAMP levels $\sim 4$ - to 8 -fold (Fig. 7A). Neither Pitstop 2 nor dynasore had any effect on basal cAMP levels (Fig. 7A). In addition, pretreatment with Pitstop 2 or dynasore for $10 \mathrm{~min}$ to block endocytosis did not inhibit total PACAP-stimulated cAMP production (Fig. 7A). In fact, the endocytosis inhibitors appeared to enhance PACAPstimulated cAMP levels by sustaining plasma membrane adenylyl cyclase activity from receptor sequestration. Low-temperature blocking of endocytosis also did not diminish culture cAMP production. Conversely, $30 \mathrm{~min}$ of PACAP stimulation at ambient temperature $\left(24^{\circ} \mathrm{C}\right)$ significantly enhanced culture cAMP production by $\sim 1$.6-fold compared with PACAP-stimulated levels at $34^{\circ} \mathrm{C}$ (Fig. $7 \mathrm{~B}$ ). These results demonstrated that the diminished
PACAP effect after inhibitor- and temperature-mediated blocking of the PAC1R complex endocytosis was not a consequence of diminished adenylyl cyclase/cAMP signaling. Furthermore, these observations suggest that PAC1R-stimulated adenylyl cyclase/ cAMP signaling was largely confined to the plasma membrane.

\section{Discussion}

The results of the present study demonstrated that the PACAPinduced increase in cardiac neuron excitability (Braas et al., 1998) was dependent on PAC1R vesicular endocytosis and signaling. The PACAP responses were essentially eliminated by pretreatment with the endocytosis inhibitors Pitstop 2 or dynasore, which block clathrin terminal domain binding and dynamin I/II GTPase activity, respectively, or by maintaining whole mounts at room temperature to halt vesicle internalization. All of these conditions dramatically suppressed PAC1R endocytosis, as shown in complementary studies using GFP-PAC1R cell lines. In contrast, pretreatment with brefeldin A to inhibit Golgi network budding and trafficking did not blunt the PACAP effect, demonstrating that plasma membrane endocytic mechanisms, rather than intracellular vesicular trafficking in general, were necessary to generate the response.

The internalization of GPCRs via clathrin-coated vesicles and the resultant formation of signaling endosomes provide a novel means to engage diverse intracellular signaling pathways that may be distinct from those activated at the plasma membrane (Calebiro et al., 2010; Scita and Di Fiore, 2010; McMahon and Boucrot, 2011). After ligand binding to GPCRs, the ensuing receptor conformational change and specific Ser/Thr phosphorylation by GPCR kinases result in $\beta$-arrestin recruitment for accessory protein scaffolding, vesicle formation, and endocytosis. PAC1Rs belong to the class B group of GPCR families that exhibit high-affinity binding for $\beta$-arrestins (Shenoy and Lefkowitz, 2003; Milligan, 2004). The resulting long GPCR/ $\beta$-arrestin association times may be particularly amenable to PAC1R internalization and robust signaling events. Upon cointernalization with GPCRs, $\beta$-arrestins have principal roles in vesicle clathrin heavy chain and AP2 adaptor protein assembly and can scaffold signaling proteins, including MAPKs, in the formation of signaling endosomes. The terminal domains of the clathrin triskelia bind to accessory protein clathrin box motifs for vesicle stabilization and recruitment of other endocytosis regulators, and the recently identified small-molecule compounds such as Pitstop 2 interfere with clathrin terminal domain binding and stall clathrinmediated endocytosis (von Kleist et al., 2011). Dynasore blocks vesicular endocytosis via a different mode. Vesicular scission from the plasma membrane requires dynamin GTPase activity and dynasore preferentially inhibits dynamin I/II (Macia et al., 2006).

PAC1Rs are internalized upon PACAP activation (May et al., 2010), as demonstrated by the PACAP-stimulated GFP-PAC1R internalization in vitro (Fig. 1), an action of PACAP blocked by Pitstop 2 and dynasore. These endocytosis inhibitors also effectively suppressed the PACAP-induced increase in cardiac neuron excitability. This did not reflect a nonspecific effect on endosomal trafficking, because brefeldin A pretreatments to suppress routing to and from Golgi cisternal networks, which may also involve clathrin mechanisms, did not blunt the PACAP effect. The inhibitor results also did not reflect alterations in neuronal membrane properties or nonspecific suppression of cell excitability. With Pitstop 2 or dynasore, cardiac neuron action potential properties were not significantly changed and, further, the addition of barium or bethanechol after PACAP and Pitstop 2 or dynasore treat- 
ment still increased excitability. Because Golgi trafficking was not necessary for the PACAP responses and neither drug appeared to depress plasma membrane signaling or excitability nonspecifically, the cellular trafficking and electrophysiological studies in aggregate implicate dynamin- and clathrin-dependent endocytosis of the PAC1R as a key step initiating the PACAP-induced change in excitability.

The PACAP-induced change in excitability also was significantly suppressed when whole-mount preparations were kept at room temperature. Reducing ambient temperature has been used previously in different systems as a mechanism to block or slow endocytosis of synaptic vesicles or ligand-gated postsynaptic receptors (Teng and Wilkinson, 2003; McCann et al., 2008). The ability of low temperatures to retard clathrin-mediated endocytosis of the PAC1R in cardiac ganglia preparations was corroborated in the GFP-PAC1R cell line studies. The temperature-sensitive step was not due to reduced cAMP production, because PACAP still activated adenylyl cyclase and increased cellular cAMP levels at room or physiological temperature. In fact, the $20 \mathrm{nM}$ PACAP concentration used in our electrophysiological studies appeared to have generated greater cAMP levels at room temperature than at $32-34^{\circ} \mathrm{C}$, suggesting that PAC1R activation of adenylyl cyclase may be predominantly at the plasma membrane and that longer PAC1R dwell time at the cell surface from low-temperature blocking of endocytosis may sustain cyclase activity for greater second messenger production. Similarly, Pitstop 2 or dynasore pretreatment tended to enhance cAMP generation, although the differences were not statistically significant. Therefore, a diminished cAMP production did not contribute to the loss of PACAP effect on excitability at room temperature or by Pitstop 2 or dynasore.

One mechanism that can contribute to the PACAP-induced increase in excitability is an enhancement of $I_{\mathrm{h}}$ (Merriam et al., 2004; Tompkins et al., 2009). Rectification during hyperpolarizing steps is an index of the activation of $I_{\mathrm{h}}$ (Edwards et al., 1995; Merriam et al., 2004). Neither Pitstop 2 nor dynasore had any effect on the extent of the voltage rectification, indicating that these inhibitors did not alter $I_{\mathrm{h}}$.

How PAC1R endocytosis supports the PACAP-induced increase in excitability remains to be established. However, GPCR receptor endocytosis and the resulting formation of signaling endosomes provides a singular means for GPCRs to recruit and activate distinct intracellular signaling cascades in spatial and temporal contexts important to the overall cellular response. For some GPCR systems, endosomal signaling appears to sustain adenylyl cyclase activity and cAMP production (Calebiro et al., 2009; Ferrandon et al., 2009); in others, GPCR endocytosis appears to be requisite for prolonged MAPK (Oakley et al., 1999; DeFea et al., 2000; Terrillon and Bouvier, 2004) and PI3K/Akt (García-Regalado et al., 2008; May et al., 2010) activation. Because intracellular cAMP and second messengers may not be readily diffusible in all cell types (Bacskai et al., 1993; Hempel et al., 1996), the delivery of signaling endosomes to specific intracellular sites may be key for local second messenger activation of regulatory substrates. Whether PAC1R endocytosis supports signaling diversification or sustains second messenger activation is still unclear. However, previous studies have shown that PACAP can sustain sympathetic neuronal culture ERK1/2 phosphorylation for $>4 \mathrm{~h}$ (May et al., 2010). PACAP-induced increases in excitability can be suppressed markedly with MEK inhibitors (Tompkins and Parsons, 2008). Therefore, MEK/ERK activation from PAC1R endosomes may be a means of PAC1R-mediated change in neuronal excitability. To examine this possibility, the HEK PAC1R cell lines were used to determine whether inhibiting receptor endocytosis blunts MEK/ERK activation. These ongoing experiments have demonstrated that PACAP-stimulated ERK phosphorylation, as determined by Western blot analysis, was significantly decreased under pharmacological and temperature treatment conditions that suppress PAC1R endocytosis (T. Buttolph, V. May, and R.L. Parsons, unpublished data). As in rat neonatal SCG neurons (Fig. 7), the PACAP-induced increase in HEK PAC1R cell cAMP production was not inhibited by restricting PAC1R endocytosis, suggesting that PAC1R-mediated stimulation of adenylyl cyclase signaling is predominantly a plasma membrane-associated event. These results are consistent with GPCR internalization mechanisms and support our hypothesis that many PACAP-activated signaling cascades require PAC1R endocytosis (May et al., 2010).

Interestingly, the ability of both Pitstop 2 and dynasore to suppress PACAP-induced increases in excitability was evident even if the inhibitors were applied after the neurons had already exhibited peptide-stimulated multiple-firing patterns. Our previous studies demonstrated that the effects of PACAP, even at nanomolar bath concentrations, can remain effective for $>90$ min (Tompkins and Parsons, 2008). Because the cycle of receptor internalization and reinsertion into the plasma membrane likely continues during sustained exposure to the peptide, a gradual block of the vesicular receptor-recycling process would contribute to the progressive reversal of the PACAP effect on excitability by both inhibitors. Therefore, the prolonged PAC1R-induced ERK activation times, coupled with endosome PAC1R recycling to the plasma membrane, might account for the time needed for Pitstop and dynasore to inhibit the ongoing PACAP effect (Figs. 5 and 6).

In summary, our results demonstrate that clathrin and dynamin inhibitors and low temperatures suppress PACAP effects on neuronal excitability. We suggest that these observations are consistent with the hypothesis that internalization of the PACAP/ PAC1R to form a signaling endosome contributes to the varied actions of this neuropeptide. The formation of a signaling endosome would explain why PACAP is more effective than forskolin or the cell-permeable cAMP analog 8-bromo-cAMP in increasing cardiac neuron excitability (Tompkins and Parsons, 2008). All three (forskolin, cAMP analogs, and PACAP) would increase the intracellular concentrations of cAMP. However, the creation of a signaling endosome would provide a mechanism by which PACAP more effectively recruits other downstream transduction pathways, such as the MAPK pathway, that are required for the peptide's full effect (Tompkins and Parsons, 2008). Signaling endosomes have typically been shown to be important in mediating trophic responses including cell survival, proliferation, and differentiation. The current studies suggest that the panoply of responses can be more diverse and may include regulation of neuronal excitability. Furthermore, given that many early studies of metabotropic transmitter receptor signaling and actions were completed at room temperature, it is likely that significant actions mediated through these receptors were missed, especially if a comparable temperature dependence exists for these GPCRs.

\section{References}

Adams DJ, Cuevas J (2004) Electrophysiological properties of intrinsic cardiac neurons. In: Basic and clinical neurocardiology (Armour JA, Ardell JL, eds), pp 1-60. Oxford: Oxford UP.

Bacskai BJ, Hochner B, Mahaut-Smith M, Adams SR, Kaang BK, Kandel ER, Tsien RY (1993) Spacially resolved dynamics of CAMP and protein kinase A subunits in Aplysia sensory neurons. Science 260:222-226. CrossRef Medline

Bonifacino JS, Traub LM (2003) Signals for sorting of transmembrane pro- 
teins to endosomes and lysosomes. Annu Rev Biochem 72:395-447. CrossRef Medline

Braas KM, May V (1999) Pituitary adenylate cyclase-activating polypeptides directly stimulate sympathetic neuron neuropeptide $\mathrm{Y}$ release through $\mathrm{PAC}_{1}$ receptor isoform activation of specific intracellular signaling pathways. J Biol Chem 274:27702-27710. CrossRef Medline

Braas KM, May V, Harakall SA, Hardwick JC, Parsons RL (1998) Pituitary adenylate cyclase-activating polypeptide expression and modulation of neuronal excitability in guinea pig cardiac ganglia. J Neurosci 18:9766-9779. Medline

Calebiro D, Nikolaev VO, Gagliani MC, de Filippis T, Dees C, Tacchetti C, Persani L, Lohse MJ (2009) Persistent cAMP-signals triggered by internalized G-protein-coupled receptors. PLoS Biol 7:e1000172. CrossRef Medline

Calebiro D, Nikolaev VO, Persani L, Lohse MJ (2010) Signaling by internalized G-protein-coupled receptors. Trends Pharmacol Sci 31:221-228. CrossRef Medline

Calupca MA, Vizzard MA, Parsons RL (2000) Origin of pituitary adenylate cyclase-activating polypeptide (PACAP)-immunoreactive fibers innervating guinea pig parasympathetic cardiac ganglia. J Comp Neurol 423:26-39. CrossRef Medline

Connors EC, Ballif BA, Morielli AD (2008) Homeostatic regulation of Kv1.2 potassium channel trafficking by cyclic AMP. J Biol Chem 283: 3445-3453. CrossRef Medline

Cuevas J, Harper AA, Trequattrini C, Adams DJ (1997) Passive and active membrane properties of isolated rat intracardiac neurons: regulation by H- and M-currents. J Neurophysiol 78:1890-1902. Medline

DeFea KA, Zalevsky J, Thoma MS, Déry O, Mullins RD, Bunnett NW (2000) beta-arrestin-dependent endocytosis of proteinase-activated receptor 2 is required for intracellular targeting of active ERK 1/2. J Cell Biol 148:12671281. CrossRef Medline

Drake MT, Zhu Y, Kornfeld S (2000) The assembly of AP-3 adaptercomplexcontaining clathrin-coated vesicles on synthetic liposomes. Mol Biol Cell 11: 3723-3736. Medline

Edwards FR, Hirst GD, Klemm MF, Steele PA (1995) Different types of ganglion cell in the cardiac plexus of guinea-pigs. J Physiol 486:453-471. Medline

Ferrandon S, Feinstein TN, Castro M, Wang B, Bouley R, Potts JT, Gardella TJ, Vilardaga JP (2009) Sustained cyclic AMP production by parathyroid hormone receptor endocytosis. Nat Chem Biol 5:734-742. CrossRef Medline

García-Regalado A, Guzmán Hernández ML, Ramírez-Rangel I, RoblesMalina E, Balla T, Vázquez-Prado J, Reyes-Cruz G (2008) G proteincoupled receptor-promoted trafficking of Gbetalgamma2-Rab1la interaction. Mol Biol Cell 19:4188-4200. CrossRef Medline

Girard BM, May V, Bora SH, Fina F, Braas KM (2002) Regulation of neurotrophic peptide expression in sympathetic neurons: quantitative analysis using radioimmunoassay and real-time quantitative polymerase chain reaction. Regul Pept 109:89-101. CrossRef Medline

Girasole AE, Palmer CP, Corrado SL, Southerland EM, Ardell JL, Hardwick JC (2010) Angiotensin II potentiates adrenergic and muscarinic modulation of guinea pig intracardiac neurons. Am J Physiol Regul Comp Physiol 301:R1391-R1399. CrossRef Medline

Hempel CM, Vincent P, Adams SR, Tsien RY, Selverston AI (1996) Soatuitemporal dynamics of cyclic AMP signals in an intact neural circuit. Nature 384:166-169. CrossRef Medline

Herskovits JS, Burgess CC, Obar RA, Vallee RB (1993) Effects of mutant rat dynamin on endocytosis. J Cell Biol 122:565-578. CrossRef Medline

Hirst J, Sahlender DA, Choma M, Sinka R, Harbour ME, Parkinson M, Robinson MS (2009) Spatial and functional relationships of GGAs and AP-1 in Drosophila and HeLa cells. Traffic 10:1696-1710. CrossRef Medline

Hoover DB, Tompkins JD, Parsons RL (2009) Differential activation of guinea pig intrinsic cardiac neurons by the PAC1 agonists maxadilan and pituitary adenylate cyclase-activating polypeptide 27 (PACAP27). J Pharmacol Exp Ther 331:197-203. CrossRef Medline

Jalink K, Moolenaar WH (2010) G protein-coupled receptors: the inside story. Bioessays 32:13-16. CrossRef Medline
Macia E, Ehrlich M, Massol R, Boucrot E, Brunner C, Kirchhausen T (2006) Dynasore, a cell-permeable inhibitor of dynamin. Dev Cell 10:839-850. CrossRef Medline

May V, Lutz E, MacKenzie C, Schutz KC, Dozark K, Braas KM (2010) Pituitary adenylate cyclase-activating polypeptide (PACAP)/PACAP ${ }_{1} \mathrm{HOP} 1$ receptor activation coordinates multiple neurotrophic signaling pathways: Akt activation through phosphatidylinositol 3-kinase gamma and vesicle endocytosis for neuronal survival. J Biol Chem 285:9749-9761. CrossRef Medline

McMahon HT, Boucrot E (2011) Molecular mechanisms and physiological functions of clathrin-mediated endocytosis. Nat Rev Mol Cell Biol 12: 517-533. CrossRef Medline

McCann CM, Tapia JC, Kim H, Coggan JS, Lichtman JW (2008) Rapid and modifiable neurotransmitter receptor dynamics at a neuronal synapse in vivo. Nat Neurosci 11:807-815. CrossRef Medline

Merriam LA, Barstow KL, Parsons RL (2004) Pituitary adenylate cyclaseactivating polypeptide enhances the hyperpolarization-activated nonselective cationic conductance, $\mathrm{I}_{\mathrm{h}}$, in dissociated guinea pig intracardiac neurons. Regul Pept 123:123-133. CrossRef Medline

Merriam LA, Roman CW, Baran CN, Girard BM, May V, Parsons RL (2012) Pretreatment with nonselective cationic channel inhibitors blunts the PACAP-induced increase in guinea pig cardiac neuron excitability. J Mol Neurosci 48:721-729. CrossRef Medline

Milligan G (2004) G protein-coupled receptor dimerization: function and ligand pharmacology. Mol Pharm 66:1-7. CrossRef Medline

Oakley RH, Laporte SA, Holt JA, Barak LS, Caron MG (1999) Association of beta-arrestin with $G$ protein-coupled receptors during clathrin-mediated endocytosis dictates the profile of receptor resensitization. J Biol Chem 274:32248-32257. CrossRef Medline

Scita G, Di Fiore PP (2010) The endocytic matrix. Nature 463:464-473. CrossRef Medline

Shenoy SK, Lefkowitz RJ (2003) Multifaceted roles of beta-arrestins in the regulation of seven-membrane-spanning receptor trafficking and signalling. Biochem J 375(pt3):503-515. CrossRef

Teng H, Wilkinson RS (2003) "Delayed" endocytosis is regulated by extracellular $\mathrm{Ca}^{2+}$ in snake motor boutons. J Physiol 551 1:103-114. CrossRef Medline

Terrillon S, Bouvier M (2004) Receptor activity-independent recruitment of betaarrestin2 reveals specific signalling modes. EMBO J 23:3950-3961. CrossRef Medline

Tompkins JD, Parsons RL (2008) Identification of intracellular signaling cascades mediating the PACAP-induced increase in guinea pig cardiac neuron excitability. J Mol Neurosci 36:292-298. CrossRef Medline

Tompkins JD, Hardwick JC, Locknar SA, Merriam LA, Parsons RL (2006) $\mathrm{Ca}^{2+}$ influx, but not $\mathrm{Ca}^{2+}$ release from internal stores, is required for the PACAP-induced increase in excitability in guinea pig intracardiac neurons. J Neurophysiol 95:2134-2142. CrossRef Medline

Tompkins JD, Ardell JL, Hoover DB, Parsons RL (2007) Neurally released pituitary adenylate cyclase-activating polypeptide enhances guinea pig intrinsic cardiac neurone excitability. J Physiol 582:87-93. CrossRef Medline

Tompkins JD, Lawrence YT, Parsons RL (2009) Enhancement of $I_{\mathrm{h}}$, but not inhibition of $I_{\mathrm{M}}$, is a key mechanism underlying the PACAP-induced increase in excitability of guinea pig intrinsic cardiac neurons. Am J Physiol Regul Integr Comp Physiol 297:R52-R59. CrossRef Medline

Vaudry D, Falluel-Morel A, Bourgault S, Basille M, Burel D, Wurtz O, Fournier A, Chow BK, Hashimoto H, Galas L, Vaudry H (2009) Pituitary adenylate cyclase-activating polypeptide and its receptors: 20 years after the discovery. Pharmacol Rev 61:283-357. CrossRef Medline

von Kleist L, Stahlschmidt W, Bulut H, Gromova K, Puchkov D, Robertson MJ, MacGregor KA, Tomlin N, Pechstein A, Chau N, Chircop M, Sakoff J, von Kries JP, Saenger W, Kräusslich HG, Shupliakov O, Robinson PJ, McCluskey A, Haucke V (2011) Role of clathrin terminal domain in regulating coated pit dynamics revealed by small molecule inhibition. Cell 146:471-484. CrossRef Medline 